\title{
Protein S Measurement
}

National Cancer Institute

\section{Source}

National Cancer Institute. Protein S Measurement. NCI Thesaurus. Code C100436.

The determination of the amount of protein S present in a sample. 